\title{
Nursing Students' Knowledge Toward Genetic Topics: A Cross-Sectional Study in Central Java, Indonesia
}

\author{
Niken Safitri Dyan Kusumaningrum ${ }^{1 \star}$ and Meira Erawati ${ }^{2}$ \\ ${ }^{1}$ Adult Nursing Division, Department of Nursing, Faculty of \\ Medicine, Diponegoro University, Jl. Prof. H. Soedarto, SH \\ Tembalang Semarang, Central Java, Indonesia 50265 \\ ${ }^{*}$ Corresponding author \\ Niken Safitri Dyan Kusumaningrum, Department of Nursing, Diponegoro \\ University, Indonesia, Phone: +6281228052220; fax: +6224 76480919, \\ ${ }^{2}$ Pediatric Nursing Division, Department of Nursing, Faculty \\ of Medicine, Diponegoro University, Jl. Prof. H. Soedarto, SH \\ Tembalang Semarang, Central Java, Indonesia 50265 \\ E-mail: niken.safitridk@fk.undip.ac.id or niken.dyan@gmail.com \\ Submitted: 16 Sep 2018; Accepted: 23 Sep 2018; Published: 30 Sep 2018
}

\begin{abstract}
Purpose: To identify nursing students' knowledge about genetics.
\end{abstract}

\begin{abstract}
Methods: A descriptive with a cross-sectional approach was used in this study. Eligible participants were recruited from a convenience sample at nine school of nursing in Central Java, Indonesia. Survey were distributed to 1691 nursing students attend the class. The modification of "The Genetic Needs Assessment Survey" was used. There were 43 questions divided in 3 sections/ domains. The questionnaire covers 3 domain, including perceive knowledge of human principles and disorders; comfort regarding genetics; and educational methods of teaching genetic topics. Also, there were 4 demographic data including age, gender, semester grade, and previous degree have been assessed. Descriptive statistics were used to explain results from data collected.
\end{abstract}

Results: There were 1635 nursing students participated in this study. The response rate was $96.7 \%$. More participants feel confident when they choose "minimal knowledge" in terms of genetic (e.g., DNA - RNA structure and function). However, they also choose "no knowledge of this topic) to pattern inheritance terms. The majority of students were not familiar to genetic disease, for example trisomy 13, trisomy 18, trisomy 21, and Huntington's disease. Students also stated that they feel more comfortable to learn about genetics through lecture, small group discussion, and roleplay.

Conclusion: Nursing students'knowledge concerning genetics still low. This knowledge will affect quality of nursing care given to the patient. Thus, genetics topic should be included in nursing curriculum at any level of education.

Keywords: curricula; genetic diseases; genetic disorders; nursing education: nursing students

\section{Introduction}

Genetics as a basic for any health condition has a major role to hold any disorders. In nursing, genetic knowledge can be used to understand the basic concept of disorders thus it can be used to select and monitor an appropriate treatment. Besides that, it also used to collect the information of family health history [1]. It is important to be knowledgeable about family health history in order to better prepare the future health and preventive care [2].

In order to conduct a comprehensive physical and health assessments, it is needed to integrate all genetic and genomic understanding that have been affected by environment and risk factors. Nurses need to provide a fact about selective genetic information. Practice and application of this knowledge should be guided to increase the quality of nurse, especially in genetic topics. Modern nursing education program need to convince genetics and genomic knowledge for all nurses in order to bridge nursing services at any levels of health practice [3].
Comprising of genetics in nursing curriculum is not a new paradigm. The International Society of Nurses in Genetics (ISONG), as a nursing organization of human genetics and genomic specialty, has established a standards of practice to guide nurses in the activities and responsibilities [4]. Some previous studies have also recommended genetic integration into nursing programs [5-7].

In Indonesia, the human genetic program has already started with formal university teaching. In the early 1960s, an analysis of chromosome in health services has also introduced. Furthermore, some molecular basis of physical disorder were also investigated [8]. However, it is only known in medical. Nursing never saw such condition as appropriate are need to be learned, either in clinical practice or in education.

Indonesian nursing program has not integrate genetics into curricula yet. Although a clinical genetics has been growth fast, however, it is not well-known in nursing area. Nursing still less aware about genetic condition [9]. It is very rare to discuss genetic topics when learning or daily practice. While, an understanding and mastery of 
basic and principles of genetic can provide a foundation to improve nursing existence to deliver a comprehensive and holistic care [10].

The development of integration of genetic topics in nursing education has been reported in several studies. It involve any level of education [11]. The strategic plan and a recommendation were provided in order to share these information $[12,13]$. In order to initiate an awareness in genetic topic, this objective of the study was to identify genetic knowledge of nursing students.

In genetic sciences, understanding between human health and illness is important. Genetics, actually, is a fundamental concept related to genetic and genomic basic of all disorders. Nurses will need to demonstrate nursing care for example how to identify patient's main complaint, drawing a pedigree as family health history report, formulating an outcome based on the patient's condition, etc.

Genetic and genomic skills are an integral part of nursing area although there are still many limitations [3]. There are many basic skills in genetics and genomics required by registered nurses. There have explained by American Association of College for Nursing (AACN), National Coalition for Health Professional Education in Genetics (NCHPEG), and National Council of State Boards of Nursing (NCSBN) [14]. Furthermore, two essentials competencies have been assigned by a committee in order to guide the implementation of genetic topics in nursing. It is divided to professional responsibilities and professional practice domain [1]. The professional responsibilities is needed by all nurses to do professional role activities. It involved genetic knowledge and skills required in competent nursing practice. While the professional practice domain consist of five nursing process that integrate genetic knowledge include assessment, nursing diagnosis, intervention, implementation, and evaluation.

Teaching nurses regarding genetic has begun many decades ago. However, years later, genetic integration in nursing curriculum has increase rapidly. There are previous studies regarding integration of genetic in nursing curriculum $[7,11,15-18]$. The application and integration of genomic information in clinical need the involvement of many areas in nursing. Likewise the application and integration in nursing education. Needs analysis of genetic and genomic material in nursing will give a recommendation to enter a genetic content into the nursing curriculum. Student will have a good understanding to the genetic basic elements when it is described at the beginning of program. After that, an advanced genetic content will be given to the next phase, step by step during the nursing program.

In order to incorporate genetic content in nursing curriculum, it is required many steps $[1,13,18]$. The process consist of six step. The first is including genetic and genomic content to the lecture. Second, the project and task about genetic and genomic knowledge need to be integrated into course. Besides that, objectives and curriculum need to be consistent discuss about genetic and genomic. Then, faculty can also develop an elective course that consist of genetic and genomic content. And the last one is interdisciplinary collaboration should be prepared to design courses and curricula [1].
Looking from previous description, it is concluded that genetic knowledge is very important. So, nursing students' knowledge about genetics is needed in this study.

Methods

Study design

A descriptive with a cross-sectional approach was used in this study.

Setting and sample

This study was carried out in 2015 to 2016 at nine school of nursing in Central Java, Indonesia. The total number of bachelor nursing students participated in this study was 1635 of 1691 (response rate $=96.7 \%$ ). The participation to this survey was voluntary for each students who registered at that nine nursing school.

\section{Ethical considerations}

This study's protocol was approved by the Institutional Review Board of the X University (Approval no. 145/EC/2014). The participants were informed about the aim and procedure of this study before providing written consent.

\section{Measurements}

1) Demographic characteristics

There were 4 demographic data including age, gender, semester grade, and previous degree that included. Age range was 17 to 45 years old. Semester grade was categorized as freshmen, sophomore, junior, senior, and profession. Previous of education was divided into senior high school, Islamic senior high school, vocational high school, nursing diploma, and others.

\section{2) Genetic knowledge}

The understanding of current medical genetic knowledge has been evaluated using the Genetics Needs Assessment Survey [19]. It has been modified and the end revealed 60 -items consisted of 44-Likertitems about perceive knowledge of human genetic principles and disorders; 6 questions asking about comfort regarding genetics, and 6 items identify educational methods of teaching genetics.

\section{Data collection}

The survey was conducted in a cross-sectional design. This was a quantitative method. Data collection carried out from March 2015 to November 2016. All questionnaires were distributed to students at the class. Students were given a brief explanation of the study before the questionnaires were distributed. Respondents were kept anonymous. A total of 1691 sets of questionnaires were distributed and 1635 were returned.

\section{Data analysis}

The data ware analyzed using statistic software. Univariate analysis was performed to describe the results. The frequencies and percentages were used to describe results.

\section{Results}

Demographic characteristics

A total of 1635 students were participated in study. The most of students were female with the mean age was 20.4 years with range of $17-45$ years. More freshmen students participated in this study (28.1\%). The demographic characteristics of students are presented in Table 1. 


\begin{tabular}{|c|c|c|}
\hline Characteristics & n & $\%$ \\
\hline \multicolumn{3}{|l|}{ Gender } \\
\hline Male & 391 & 23.9 \\
\hline Female & 1244 & 76.1 \\
\hline \multicolumn{3}{|l|}{ Semester grade } \\
\hline Freshmen & 460 & 28.1 \\
\hline Sophomore & 455 & 27.8 \\
\hline Junior & 389 & 23.8 \\
\hline Senior & 321 & 19.6 \\
\hline Profession & 10 & 0.6 \\
\hline \multicolumn{3}{|l|}{ Previous degree of education } \\
\hline Senior high school (general) & 1386 & 84.8 \\
\hline Islamic Senior high school & 41 & 2.5 \\
\hline Vocational high school & 147 & 8.9 \\
\hline Nursing diploma & 59 & 3.6 \\
\hline Esthetic diploma & 1 & 0.1 \\
\hline Faculty of Medicine & 1 & 0.1 \\
\hline
\end{tabular}

Perceive knowledge of human genetic principles and disorders

In genetic terminology, more participants feel confidence when they chose "minimal knowledge" in specific terms (e.g., DNA - RNA structure and function, DNA replication, transcription, protein synthesis, and mutation). However, there were respondents also chose "no knowledge of this topic, especially to pattern inheritance terms (autosomal dominant, autosomal recessive, $\mathrm{x}$-linked, and mitochondrial). Table 2 give detail information concerning students' perceived knowledge about genetic topics.

Table2: Respondents' Perceived Knowledge about Genetics Topics $(\mathbf{N}=1635)$

\begin{tabular}{|c|c|c|c|c|}
\hline Genetics topics & $\begin{array}{l}\text { No knowledge of this } \\
\text { topic }(\mathrm{n} ; \%)\end{array}$ & $\begin{array}{l}\text { Minimal knowledge } \\
\text { of this topic }(n ; \%)\end{array}$ & $\begin{array}{l}\text { Some knowledge of } \\
\text { this topic }(n ; \%)\end{array}$ & $\begin{array}{l}\text { High level of knowledge } \\
\text { of this topic (n; \%) }\end{array}$ \\
\hline \multicolumn{5}{|l|}{ Genetic terminology } \\
\hline DNA: structure and function & $142(8.7)$ & $728(44.5)$ & $665(40.7)$ & $51(3.1)$ \\
\hline RNA: structure and function & $221(13.5)$ & $723(44.2)$ & $600(36.7)$ & $44(2.7)$ \\
\hline DNA replication & $291(17.8)$ & $705(43.1)$ & $535(32.7)$ & $63(3.9)$ \\
\hline Mitosis & $271(16.6)$ & $628(38.4)$ & $585(35.8)$ & $87(5.3)$ \\
\hline Meiosis & $311(19.0)$ & $616(37.7)$ & $563(34.4)$ & $83(5.1)$ \\
\hline Transcription & $522(31.9)$ & $659(40.3)$ & $379(23.2)$ & $48(2.9)$ \\
\hline Translation & $517(31.6)$ & $653(39.9)$ & $387(23.7)$ & $49(3.0)$ \\
\hline Protein synthesis & $229(14.0)$ & $665(40.7)$ & $601(36.8)$ & $88(5.4)$ \\
\hline $\begin{array}{l}\text { Mutation Autosomal Dominant } \\
\text { Inheritance Pattern }\end{array}$ & $189(11.6)$ & $667(40.8)$ & $607(37.1)$ & $114(6.9)$ \\
\hline $\begin{array}{l}\text { Autosomal Recessive Inheritance } \\
\text { Pattern }\end{array}$ & $715(43.7)$ & $521(31.9)$ & $315(19.3)$ & $55(3.4)$ \\
\hline X-linked Inheritance Pattern & $947(57.9)$ & $478(29.2)$ & $168(10.3)$ & $27(1.7)$ \\
\hline Mitochondrial Inheritance Pattern & $834(51.0)$ & $533(32.6)$ & $224(13.7)$ & $28(1.7)$ \\
\hline Genogram & $471(28.8)$ & $478(29.2)$ & $429(26.2)$ & $139(8.5)$ \\
\hline \multicolumn{5}{|l|}{ Genetic Condition } \\
\hline Cystic Fibrosis & $828(50.6)$ & $526(32.2)$ & $216(13.2)$ & $44(2.7)$ \\
\hline $\mathrm{Ca}$ Ovarium & $86(5.3)$ & $541(33.1)$ & $697(42.6)$ & $183(11.2)$ \\
\hline Colon cancer & $222(13.6)$ & $573(35.1)$ & $588(35.9)$ & $150(9.2)$ \\
\hline Hemochromatosis & $857(52.4)$ & $514(31.4)$ & $207(12.7)$ & $37(2.3)$ \\
\hline Sickle Cell Disease & $957(58.5)$ & $452(27.7)$ & $180(11.0)$ & $29(1.8)$ \\
\hline
\end{tabular}




\begin{tabular}{|c|c|c|c|c|}
\hline Thalassemia & $559(34.2)$ & $552(33.8)$ & $392(23.9)$ & $80(4.9)$ \\
\hline Fragile $\mathrm{X}$ & $1121(68.6)$ & $389(23.8)$ & $103(6.3)$ & $16(1.0)$ \\
\hline Huntington's Disease & $1146(70.1)$ & $367(22.5)$ & $94(5.8)$ & $19(1.2)$ \\
\hline Familial hypercholesterolemia & $985(60.2)$ & $460(28.1)$ & $155(9.5)$ & $23(1.4)$ \\
\hline Neurofibromatosis & $908(55.5)$ & $523(32.0)$ & $166(10.2)$ & $29(1.8)$ \\
\hline Osteogenesis Imperfecta & $1031(63.1)$ & $447(27.3)$ & $125(7.7)$ & $24(1.5)$ \\
\hline Trisomy 21 (Down Syndrome) & $1167(71.4)$ & $354(21.7)$ & $91(5.6)$ & $17(1.0)$ \\
\hline Trisomy 18 (Edward Syndrome) & $1221(74.7)$ & $314(19.2)$ & $80(4.9)$ & $12(0.7)$ \\
\hline Trisomy 13 (Patau Syndrome) & $1217(74.4)$ & $313(19.1)$ & $84(5.1)$ & $14(0.9)$ \\
\hline Turner Syndrome & $873(53.4)$ & $537(32.8)$ & $188(11.5)$ & $22(1.4)$ \\
\hline Kleinefelter Syndrome & $1009(61.7)$ & $431(26.4)$ & $164(10.0)$ & $19(1.2)$ \\
\hline \multicolumn{5}{|l|}{ Others } \\
\hline Polymerase Chain Reaction (PCR) & $1130(69.1)$ & $380(23.2)$ & $98(6.0)$ & $17(1.2)$ \\
\hline
\end{tabular}

When the participants have to answer the genetic condition topics, the majority of them had answered that they perceived were not familiar to genetic disease, such as trisomy 18 , trisomy 13 , trisomy 21 , Huntington's disease, fragile X syndrome, osteogenesis imperfecta, Kleinefelter syndrome, and familial hypercholesterolemia. Most of participants $(69.1 \%)$ also stated that they have no knowledge on Polymerase Chain Reaction (PCR) terms.

Comfort in genetics topics

In the section of students' understanding in genetic terms, the majority stated that they can define that terms. More than sixty per cent of them can describe all terminology clearly. That results indicated that most of the terms can be interpreted accurately by students. Figure 1 give detail information on students' understanding in genetic terms.

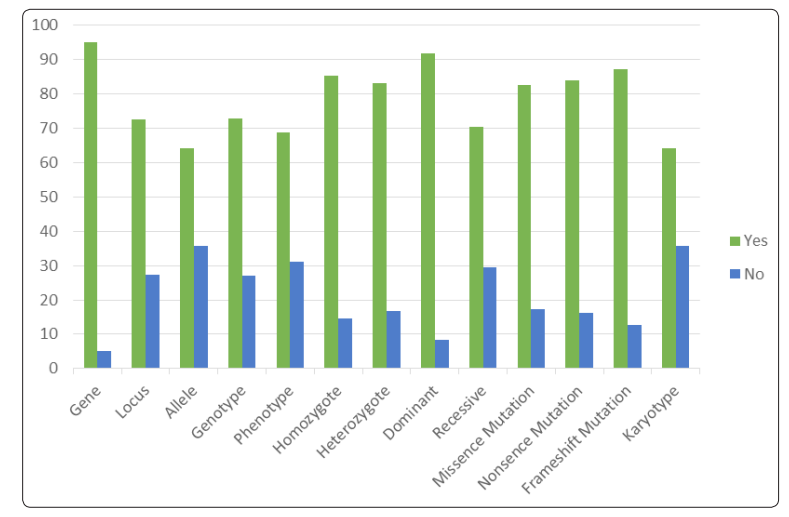

Figure 1: Students' Understanding of Genetics Terms

This study also asked the information about participants' opinion of their own comfort level concerning medical genetics knowledge. It is illustrated in figure 2. Most of the students answered that they more comfort to find a specific genetic disease information on the internet (91.9\%) and using Online Mendelian in Man (OMIM) $(83.8 \%)$. However, when asked to recommend a specific support group to a genetic patient, they stated were not comfort.

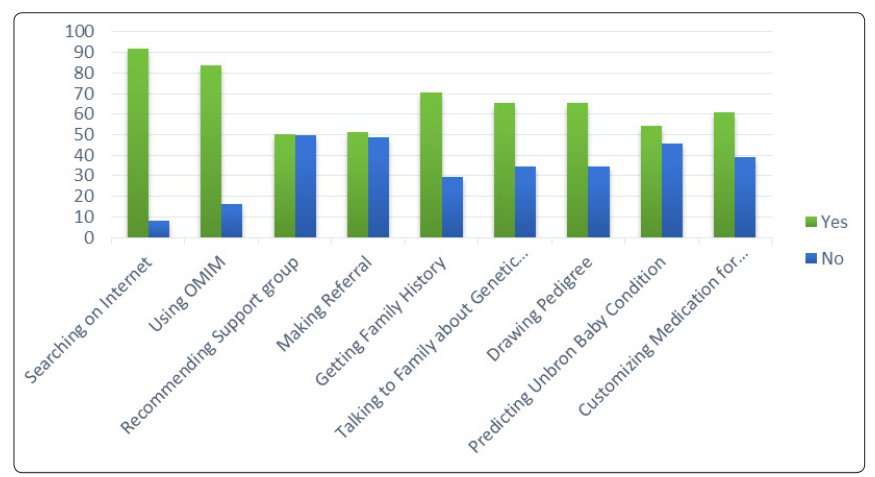

Figure 2: Students' Comfort Regarding Activity Related to Genetic Topics

Educational methods of teaching genetics

In the end of questionnaire, students were asked about educational activities that they perceived can improve their knowledge/ understanding of genetics. Figure 3 illustrated educational methods used in genetics education. Most of the students $(94.6 \%)$ perceived that lectures will improve their understanding of genetics topics. They also stated that small group discussion (SGD) was considered can develop their knowledge.

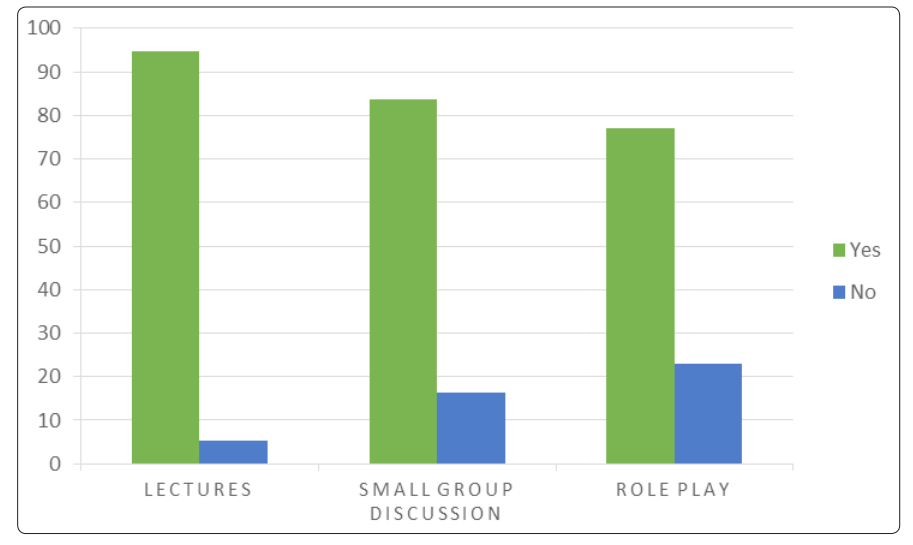

Figure 3: Educational Methods Used in Genetics Education 
Discussion

Students who participated in this study were all undergraduate nursing students either bachelor or internship level. Long time ago, nursing education is primarily conducted at senior high school. However, now the trends has changed. Government through the university has given a strong support in education for nurses [20]. With this changes, the policies for nursing curriculum certainly will also change. By increasing of genetic diseases incidence, nursing profession as one part that provides health services need to organize themselves to welcome this situation. This is in line with the Human Genome Project in which rapidly improve. Thus, genetics topic have to include into nursing curriculum in order to increase the nurses existence in giving nursing care.

Genetics is not widely known in nursing, especially in Indonesia. Genetics is often regarded as an abstract things, so cannot be handled properly. Therefore, studying the genetics is considered as learn something that is uncertain and cannot be measured. Whereas nursing have rigorous indicators in establishing outcome. The result, this particular area is not considered to be specifically included in nursing education. Even the Association of Indonesian Nurse Education Center (AINEC) have been integrate genetic topic in nursing curricula yet. Nevertheless, it has been suggested that genetics be considered as a basic and an important part of the preliminary science in nursing practice [21].

The result showed that nursing students have poor of knowledge on genetics topic. It is in line with a previous study that revealed many nursing students' have limited knowledge, perception, and attitudes regarding medical genetics [19]. Additionally, this study also found that over sixty per cent of the nursing students perceived more understanding in basic genetic terms (e.g. gene) than specific genetic language. It is according to previous research indicated that nurses mostly stressed Mendelian genetics [22]. However, in general, nursing students feel comfortable learning about genetic concept [9]. These conditions not only occur in nursing students, but also happen to nurses who already work at the health service. Nevertheless limitations in knowledge about the genetics would encourage nurses to improve their knowledge and skills in dealing with cases of genetics in the future [21]. This indicates that genetics concepts, principles, and genetics conditions across the life span need to be integrated into the material of study for discussion in a while. Assistance to genetics in nursing practice should be continued until the clinical practice in the actual health care setting [23]. Furthermore, the newest study also demonstrated that nurses need more education about genetic information that includes how to assess risk in an inherited cancer family history [24].

All nursing faculty should begin to respond with genetic issues before this topic can be included in the curriculum [6]. Understanding the definition of genetic terms will help the student recognize genetic appropriately. The genetic guidelines will also help the faculty members in teaching in nursing programs. The experts in genetic nursing have arrange recommendations concerning the integration of genetic competencies into existing course [5,15,17]. Furthermore, faculty members must decide how the genetic content will be infused into the bachelor of nursing curriculum [11]. Nursing faculty will graduate more professional nurses who are proficient in dealing with genetic problems in patients. Nurses understanding in basic competencies in genetics include nursing assessment, diagnosis, determine the outcomes, implementation, and evaluation. Those activities consist of identification, provide an education, patient care, and also patient support [25]. The previous study also stated that a family health history should be included to nursing curriculum in order to provide a basic information on this part effectively when in a clinical practice [2].

Technology and information plays an important role in genetic knowledge spreading. This can involve mass media, electronic, or manually way. Now, students at school of nursing have a high creativity and strategy in learning of certain material. This study revealed that most of students answered that they chose to find the information on a specific genetic disease on the internet. It is line with previous studies stated that more nursing students accessing genetic information on the internet $[9,26]$.

Many learning methods in genetic education can be used to improve student comfort in genetic topic. It is resulted that the majority of students stated that lecture is the most method chosen to increase genetic knowledge. Similar results were also demonstrated in many previous studies [9,22,27]. People in Indonesia prefer to choose passive learning. It may be caused they fell unconfident to do something that are not sure which is the false and the true. Besides that, they also more happy when they get a description from expert.

In a study described the integration of genetic content into nursing curriculum, it is stated that its program will begin to familiarize student with necessary terminology while preparing them with the essential competencies [1,11]. Furthermore, the nursing panel in genetic has been issued the blueprint that gives the framework to improve genetics and genomics integration into nursing curricula $[13,28]$. Consequently, incorporating genetic and genomic in nursing can lead to increase nurses' competencies in genetic and genomic services that finally will support its use on the research, also in epigenetic involvement [29].

\section{Conclusions}

It is concluded that nursing students' knowledge on the genetic topics in Central Java is poor. There are many terminology that is unfamiliar to nursing students. Several of learning techniques can be used to improve students' knowledge. It is recommended that genetic topic should be integrated in nursing curriculum at any level of education.

\section{Acknowledgement}

The authors acknowledge and thank all students who participated in this study.

\section{Conflicts of Interest}

We have no conflict of interest to declare.

\section{References}

1. Consensus Panel on Genetic/ Genomic Nursing Competences. Essential of genetic and genomic nursing: competencies, curricula guidelines, and outcome indicators [Internet]. 2nd Ed. Maryland: American Nurses Association; 2009 [cited 20. p. 80. Available from: http://www.genome.gov.

2. Ford CD, Rooks RN, Montgomery M (2016) Family health history and future nursing practice: implications for undergraduate nursing students. Nurse Educ Pract 21: 100-103. http://doi.org/10.1016/j.nepr.2016.10.004

3. Giarelli E, Reiff M (2012) Genomic literacy and competent 
practice: call for research on genetics in nursing education. Nurs Clin North Am 47: 529-45.

4. American Nursing Association and International Society of Nurses in Genetics. Genetics/ genomic nursing: scope \& standards of practice [Internet]. Maryland: Nursesbooks.org; 2007. p. 119. Available from http://www.nursingworld.org.

5. Hetteberg CG, Prows C a, Deets C, Monsen RB, Kenner C a (1999) National survey of genetics content in basic nursing preparatory programs in the United States. Nurs Outlook 47: 168-180.

6. Jenkins JF, Prows C, Dimond E, Monsen R, Williams J (2001) Recommendations for educating nurses in genetics. J Prof Nurs 17: 283-290.

7. Burke S, Kirk M (2006) Genetics education in the nursing profession: literature review. J Adv Nurs 54: 228-237.

8. World Health Organization. Identifying regional priorities in the area of human genetics in SEAR [Internet]. Bangkok: WHO; 2004. p.12. Available from http://www.who.int.

9. Erawati M, Kusumaningrum NSD (2015) A Pilot study of nursing students' knowledge towards genetic topics. Nurse Media J Nurs 5: 24-33.

10. Lea DH (2009) Basic genetics and genomics : a primer for nurses. Online J Issues Nurs 14: 1-11.

11. Sharoff L (2015) Genetics and genomics integration into undergraduate nursing education. J Nurs Educ Pract 5: 13-18.

12. Calzone K a., Jenkins J, Prows C a., Masny A (2011) Establishing the outcome indicators for the essential nursing competencies and curricula guidelines for genetics and genomics. J Prof Nurs 27: 179-191.

13. Genomic Nursing State of the Science Advisory Panel (2013) A Blueprint for Genomic Nursing Science. J Nurs Scholarsh 45: 96-104.

14. Camak DJ (2016) Increasing importance of genetics in nursing. Nurse Educ Today 44: 86-91. http://doi.org/10.1016/j. nedt.2016.05.018

15. Hetteberg C, Prows C a (2002) A checklist to assist in the integration of genetics into nursing curricula. Nurs Outlook 52: $85-88$.

16. Daack-hirsch S, Jackson B, Belchez CA, Elder B, Hurley R, Kerr P, et al. (2013) Integrating genetics and genomics into nursing curricula you can do it too: nursing education genetics genomics case study undergraduate curriculum. Nurs Clin NA 48: 661-669. http://doi.org/10.1016/j.cnur.2013.08.005

17. Horner SD, Abel E, Taylor K, Sands D (2004) Using theory to guide the diffusion of genetics content in nursing curricula. Nurs Outlook 52: 80-84.

18. Williams JK, Prows CA, Conley YP, Eggert J, Kirk M, Nichols F (2011) Strategies to prepare faculty to integrate genomics into nursing education programs. J Nurs Scholarsh 43: 231-238.

19. Maradiegue A, Edwards QT, Seibert D, Macri C, Sitzer L (2005) Knowledge, perceptions, and attitudes of advanced practice nursing students regarding medical genetics. J Am Acad Nurse Pract 17: 472-479.

20. Shields L, Hartati LE (2003) Nursing and health care in Indonesia. J Adv Nurs 44: 209-2016.

21. Kim MY (2003) The Nurses' knowledge and perception of their role in genetics. J Korean Acad Nurs 33: 1083-1092.

22. Hsiao C-Y, Lee S-H, Chen S-J, Lin S-C (2013) Perceived knowledge and clinical comfort with genetics among Taiwanese nurses enrolled in a RN-to-BSN program. Nurse Educ Today 33: 802-807.

23. Sharoff L (2016) Perceived genetic knowledge among prelicensure undergraduate nursing students. J Nurs Educ Pract 7.

24. Eggert J (2017) Genetics and genomics in oncology nursing. Nurs Clin North Am 52: 1-25.

25. Charlesworth B, Charlesworth D, Barton NH (2003) The effects of genetic and geographic structure on neutral variation. Annu Rev Ecol Evol Syst 34: 99-125.

26. Dodson CH, Lewallen LP (2011) Nursing students' perceived knowledge and attitude towards genetics. Nurse Educ Today 31: 333-339.

27. Nicol MJ (2002) The teaching of genetics in New Zealand undergraduate nursing programmes. Nurse Educ Today 22: 401-8.

28. De Sevo MR (2013) Competency of nurse educators in genetics/ genomics knowledge. J Nurs Educ Pract 3: 123-129.

29. Clark AE, Adamian M, Taylor JY (2013) An overview of epigenetics in nursing. Nurs Clin North Am 48: 649-59.
Copyright: (C2018 Niken Safitri Dyan Kusumaningrum. This is an openaccess article distributed under the terms of the Creative Commons Attribution License, which permits unrestricted use, distribution, and reproduction in any medium, provided the original author and source are credited. 